\title{
Dimsyl Anion Enables Visible-Light-Promoted Charge Transfer in Cross-Coupling Reactions of Aryl Halides
}

\author{
Lei Pan, Maria Victoria Cooke, Amara Spencer, and Sébastien Laulhé* \\ Department of Chemistry and Chemical Biology, Indiana University-Purdue University Indianapolis, Indianapolis, IN \\ 46202, United States
}

\begin{abstract}
A simple and mild methodology is reported for visible-light-promoted synthesis of unsymmetrical chalconides enabled by dimsyl anion in the absence of transition-metals or photoredox catalysts. The cross-coupling reaction between aryl halides and diaryl dichalconides proceeds in good to excellent yields with electron-rich, electron-poor, and heteroaromatic moieties. Mechanistic investigations using UV-Vis spectroscopy, time-dependent density functional theory (DFT) calculations, and control reactions suggest that dimsyl anion forms an electron-donor-acceptor (EDA) complex capable of absorbing blue light, leading to a charge transfer responsible for generation of aryl radicals from aryl halides. This previously unreported mechanistic pathway may be applied to other light-induced transformations performed in DMSO in the presence of bases and aryl halides.
\end{abstract}

Diaryl sulfides, selenides, and tellurides are valuable moieties across all chemical sectors from pharmaceuticals to material sciences. ${ }^{1}$ Consequently, the construction of these carbonchalconide bonds has attracted significant interest. ${ }^{2}$ Most methods rely on transition-metal catalysis for the crosscoupling of aryl halides ${ }^{3,4}$ with aryl chalconides (Scheme 1A). High temperatures and expensive ligands are often required to avoid thiolate-induced catalyst deactivation and poisoning. ${ }^{5}$ Additionally, the thiols and selenols used in these reactions are unstable, have strong unpleasant odors, ${ }^{6}$ and some derivatives, such as stannyl selenides, ${ }^{7}$ have increased toxicity making them unsuitable for large-scale reactions. Milder reaction conditions using photoredox strategies have been developed (Scheme 1B), ${ }^{8,9}$ but these methods often require the use of expensive photocatalysts. A limited number of catalyst-free photo-induced methodologies for $\mathrm{C}-\mathrm{S}$ bond formation from aryl halides exist, ${ }^{2 \mathrm{~d}, 10}$ but they were not shown to work across group 16 elements.

Over the past decade, there has been an emergence of transition-metal-free cross-coupling reactions of aryl halides utilizing tert-butoxides $(-\mathrm{O} t \mathrm{Bu})$. Initial observations demonstrated that $\mathrm{KO} t \mathrm{Bu}$ in the presence of ligands ${ }^{11}$ at high temperatures enabled the direct $\mathrm{C}-\mathrm{H}$ arylation of benzene with aryl halides. In the presence of visible-light, similar transformations of aryl halides have been achieved at room temperature, ${ }^{12}$ often using dimethyl sulfoxide (DMSO) as solvent.

Tuttle and Murphy contributed significantly in elucidating the mechanism of these metal-free transformations, ${ }^{13}$ and it was determined that in most cases $\mathrm{KO} t \mathrm{Bu}$ is not involved in the single electron transfer (SET) step. Instead, they identified various electron-donating species, such as the dimsyl anion, that are capable of performing a SET to aryl halides at high temperatures $\left(135^{\circ} \mathrm{C}\right) .{ }^{14}$ However, this work did not provide an explanation for the photo-induced activation of aryl halides in DMSO in the absence of additives. Recently, the Rossi group proposed that the dimsyl anion can be photo-excited to initiate a SET to alkyl halides, ${ }^{15}$ but an electron-donor-acceptor (EDA) complex was not observed.
Scheme 1. Current and proposed approaches to generate diaryl sulfides and selenides

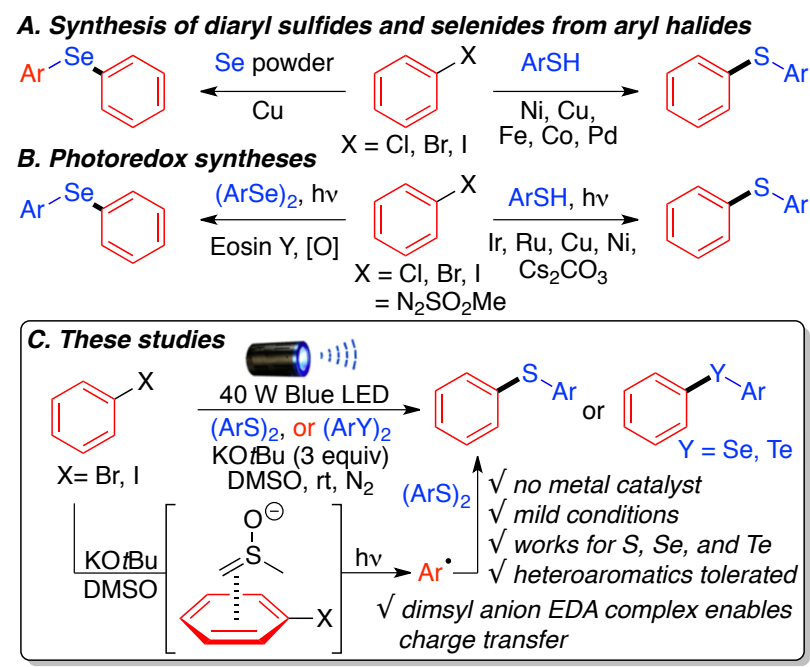

Our interest in photoinduced SET performed by $\mathrm{KO} t \mathrm{Bu}$, recently led us to identify a halogen-bonded EDA complex capable of $\mathrm{C}-\mathrm{H}$ aminations. ${ }^{16}$ Herein, an unprecedented EDA complex between dimsyl anion and aryl halides is reported that is responsible for a photo-induced activation of aryl halides and enables a visible-light-promoted $\mathrm{C}-\mathrm{S}, \mathrm{C}-\mathrm{Se}$, and $\mathrm{C}-\mathrm{Te}$ cross-coupling with diaryl dichalconides (Scheme 1C). The reaction proceeds at room temperature in the absence of catalysts generating the desired products in good to excellent yields across a range of substrates. The involvement of this EDA complex is supported by UV-Vis spectroscopy, timedependent density functional theory (DFT) calculations, and experimental controls. The observation of this EDA complex provides a compelling mechanistic explanation for the SET that initiates this reaction and possibly other photo-induced transformations of aryl halides that use DMSO in the presence of base. 
We selected 4-iodoanisole (1a) and diphenyl disulfide (2a) as model reagents to optimize the reaction. No product was detected in the absence of base under inert atmosphere with DMSO as the solvent (Table 1, entry 1). In the presence of three equivalents of $\mathrm{KO} t \mathrm{Bu}$ the reaction provided the desired product in $88 \%$ isolated yield (entry 2 ). Using $\mathrm{NaO} t \mathrm{Bu}$ or $\mathrm{Li}-$ $\mathrm{O} t \mathrm{Bu}$ as base resulted in lower yields (entries 3,4) indicating the importance of solubility of the base. Other solvents such as acetonitrile $\left(\mathrm{CH}_{3} \mathrm{CN}\right)$ or dichloromethane $\left(\mathrm{CH}_{2} \mathrm{Cl}_{2}\right)$ (entries 5, 6) also gave lower yields (see full details in the Supporting Information, S4). Inorganic and organic bases $\left(\mathrm{Cs}_{2} \mathrm{CO}_{3}\right.$, $\mathrm{DABCO}$, and $\mathrm{Et}_{3} \mathrm{~N}$ ) were explored to further understand the potential role of the base in this transformation (Table 1, entries 7-9). Unfortunately, the yields for these reactions were low. The poor performance with $\mathrm{Cs}_{2} \mathrm{CO}_{3}$ (entry 7) further emphasizes that a different mechanism is at play compared to previously proposed transformations. ${ }^{2 \mathrm{~d}}$ Reducing the amount of $2 \mathrm{a}$ to 1.5 equivalent (entry 10) did not affect the reaction. Further reducing 2a to 1.1 equivalent (entry 11) lowered the yield. When the reaction was performed in dark (entry 12) no product was formed, which highlighting the fundamental role of photons. Importantly, a decrease in yield was also observed when the reaction was carried out in air (entry 13). Finally, a time study showed that for the reaction was completed in $4 \mathrm{~h}$ (entry 14)

Table 1. Optimization of reaction conditions ${ }^{a}$

\begin{tabular}{|c|c|c|c|c|}
\hline entry & base (equiv.) & $2 a$ (equiv.) & solvent $(m L)$ & yield $(\%)^{b}$ \\
\hline 1 & - & 2.0 & DMSO (1.0) & - \\
\hline $2^{a}$ & KOtBu (3.0) & 2.0 & DMSO (1.0) & $85(88)^{c}$ \\
\hline 3 & $\mathrm{NaO} t \mathrm{Bu}(3.0)$ & 2.0 & DMSO (1.0) & 76 \\
\hline 4 & $\mathrm{LiO} t \mathrm{Bu}(3.0)$ & 2.0 & DMSO (1.0) & 63 \\
\hline 5 & $\mathrm{KO} t \mathrm{Bu}(3.0)$ & 2.0 & $\mathrm{CH}_{3} \mathrm{CN}(1.0)$ & 12 \\
\hline 6 & $\mathrm{KO} t \mathrm{Bu}(3.0)$ & 2.0 & $\mathrm{CH}_{2} \mathrm{Cl}_{2}(1.0)$ & - \\
\hline 7 & $\mathrm{Cs}_{2} \mathrm{CO}_{3}(3.0)$ & 2.0 & DMSO (1.0) & 35 \\
\hline 8 & DABCO (3.0) & 2.0 & DMSO (1.0) & 38 \\
\hline 9 & $\mathrm{Et}_{3} \mathrm{~N}(3.0)$ & 2.0 & DMSO (1.0) & trace \\
\hline 10 & $\mathrm{KO} t \mathrm{Bu}(2.0)$ & 2.0 & DMSO (1.0) & 25 \\
\hline $11^{a}$ & KOtBu (3.0) & 1.5 & DMSO (1.0) & 83 \\
\hline 12 & $\mathrm{KO} t \mathrm{Bu}(3.0)$ & 1.1 & DMSO (1.0) & 59 \\
\hline $13^{d}$ & $\mathrm{KO} t \mathrm{Bu}(3.0)$ & 1.5 & DMSO (1.0) & - \\
\hline $14^{e}$ & $\mathrm{KO} t \mathrm{Bu}(3.0)$ & 1.5 & DMSO (1.0) & 53 \\
\hline $15^{f}$ & $\mathrm{KO} t \mathrm{Bu}(3.0)$ & 1.5 & DMSO (1.0) & 82 \\
\hline
\end{tabular}

${ }^{a}$ Conditions: 1a $(0.2 \mathrm{mmol}), \mathbf{2 a}$, base, solvent, room temperature around reaction flask was $35^{\circ} \mathrm{C}$ (heating caused by the LED lamp), under $\mathrm{N}_{2}, 24 \mathrm{~h} .{ }^{b}$ Yields are based on 1a, determined by ${ }^{1} \mathrm{H}$ NMR using dibromomethane as internal standard. ${ }^{c}$ Isolated yield. ${ }^{d}$ The reaction was performed in dark covered by aluminum foil. ${ }^{e}$ The reaction was performed in the air. ${ }^{f} 4$ h reaction.

We continued our study investigating the substrate scope for this transformation. The scope of aryl halides is quite broad (Scheme 2, products 1-14). Both electron-donating (OMe, $\mathrm{Me}$ ) and electron-withdrawing $\left(\mathrm{CF}_{3}, \mathrm{~F}\right)$ groups at the para positions afforded the desired cross-coupled products $3-\mathbf{6}$ in good to excellent yields (77-89\%). Highly electron-poor substrates such as 1-bromo-3,5-ditrifluoromethylbenzene also gave desired product 7 albeit in slightly lower yields $(66 \%)$. The presence of an aryl nitrile afforded product $8(33 \%)$, primarily due to hydrolysis of the cyano group. Acidic or easily hydrolysable functional groups were not well tolerated. Excellent yields were obtained when 1-iodonaphthalene and 2-bromopyridine were used as coupling partners affording products $\mathbf{9}$ and $\mathbf{1 0}$ $(92 \%$ and $93 \%)$. This promising result led us to exploration of other heteroaromatic halides, particularly those with privileged frameworks in bioactive compounds. 3-Iodopyridine and 6iodoquinoline provided desired product 11 and $\mathbf{1 2}$ in good yield (75\%). 5-Bromoquinoline afforded product 13 in 53\% yield. Finally, 2,6-dibromopyridine was efficiently coupled at both halogen sites giving product 14 in a single step (72\%).

\section{Scheme 2. Aryl halide and aryl disulfide scope ${ }^{a}$}
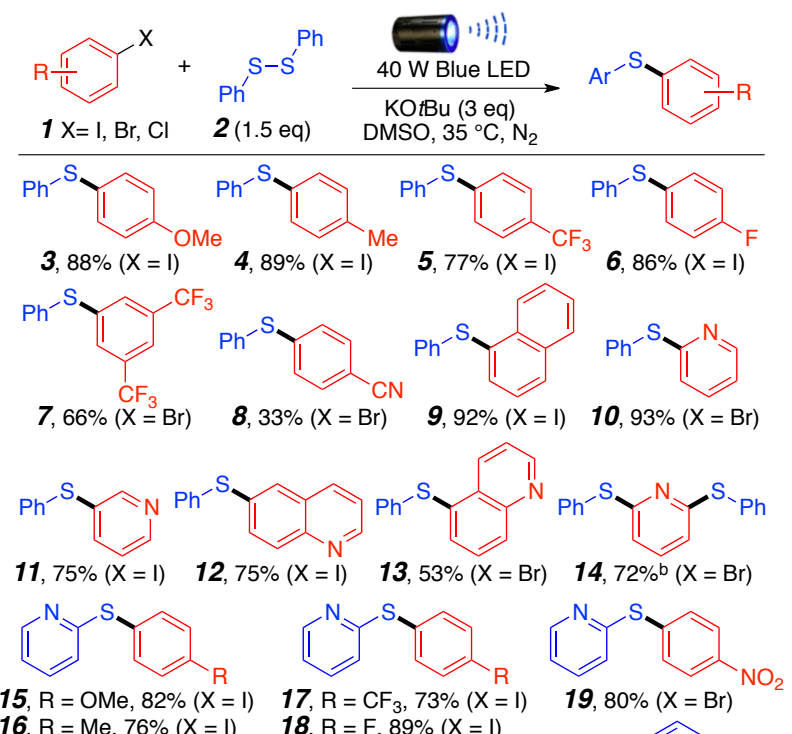

16, $R=M e, 76 \%(X=I) \quad 18, R=F, 89 \%(X=I)$
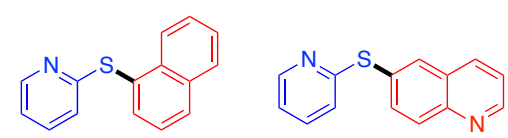

$20,84 \%(X=1)$

21, $73 \%(X=1)$

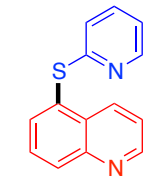

22, $75 \%(X=B r)$

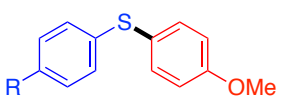

23, $\mathrm{R}=\mathrm{Me}, 88 \%(\mathrm{X}=\mathrm{I})$ 24, $\mathrm{R}=\mathrm{NH}_{2}, 22 \%(X=\mathrm{I})$

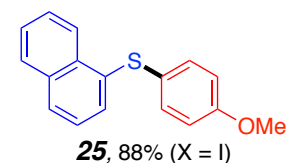

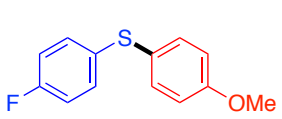

26, $83 \%(X=I)$
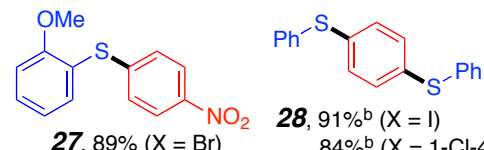

$84 \%^{b}(X=1-C l-4-1)$
${ }^{a}$ Conditions: 1 ( $\left.0.2 \mathrm{mmol}\right), 2$ (1.5 equiv.), $\mathrm{KO} t \mathrm{Bu}$ (3 equiv.), DMSO $(1 \mathrm{~mL})$, room temperature around reaction flask was $35^{\circ} \mathrm{C}$ (heating caused by the LED lamp), under $\mathrm{N}_{2}, 24 \mathrm{~h} .{ }^{b} 2$ (3 equiv.).

Various aryl disulfides were also investigated (Scheme 2, products 15-28). Product scope was extended to heteroaromatic moieties present on the disulfide, which complements those in the aryl halides. For example, 2,2'-dipyridyldisulfide reacted readily in good to excellent yields with both electronrich aryl iodides $(\mathbf{1 5}, \mathbf{1 6})$ and electron-poor aryl halides (17-19, 73-80\%) even tolerating highly electron deficient aromatic rings containing nitro $\left(\mathrm{NO}_{2}\right)$ functionalities. Having heteroaromatic moieties on both coupling partners does not negatively 
affect the yield affording products 21 and 22 in $73 \%$ and $75 \%$ yields, respectively. Both electron-rich and electron-poor aromatic rings are well tolerated in the disulfide to give products 23, 26, and $27(88 \%, 83 \%$, and 89\%). However, the presence of aniline affected product formation 24 (22\%). Finally, disubstituted product $\mathbf{2 8}$ was generated in one step in excellent yields $(91 \%)$ from 1,4-diiodobenzene, and 84\% from 1-chloro4-iodobenzene, further indicating that selected chlorinated substrates can be coupled (Scheme 2).

\section{Scheme 3. Aryl diselenide and ditelluride scope ${ }^{a}$}

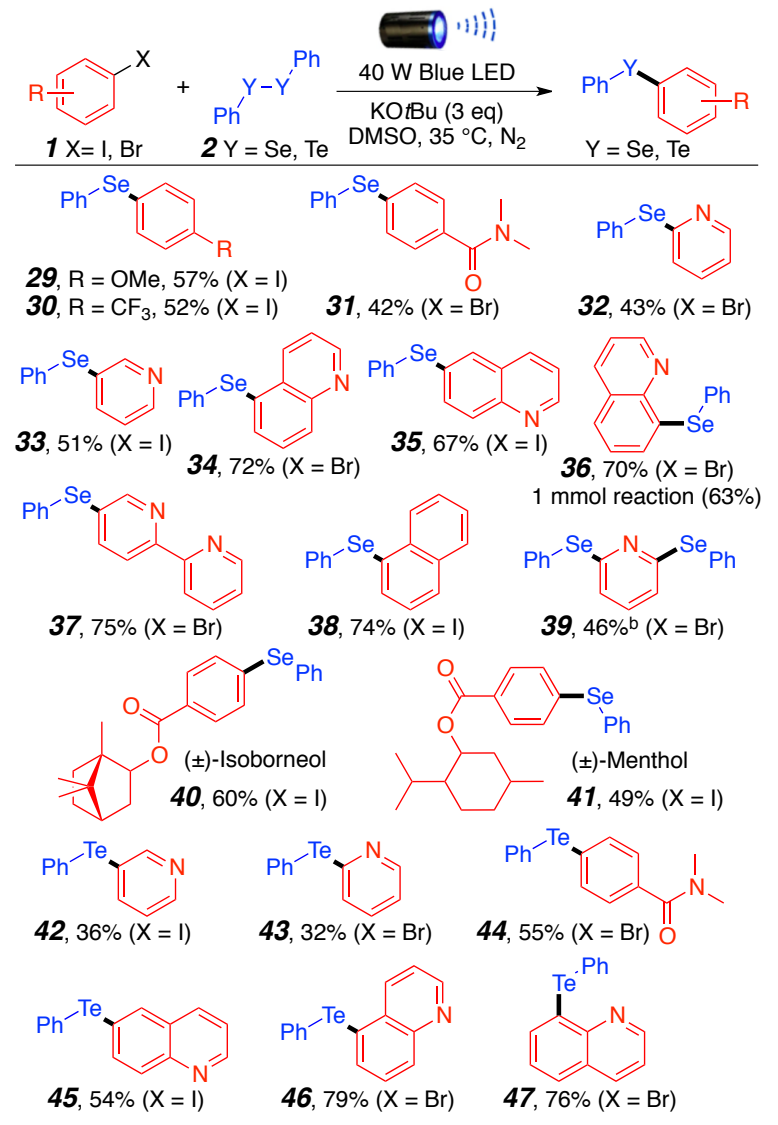

${ }^{a}$ Conditions: 1 ( $\left.0.2 \mathrm{mmol}\right), 2$ (1.5 equiv.), KO $t \mathrm{Bu}$ ( 3 equiv.), DMSO $(1 \mathrm{~mL})$, room temperature around reaction flask was $35^{\circ} \mathrm{C}$ (heating caused by the LED lamp), under $\mathrm{N}_{2}, 24 \mathrm{~h} .{ }^{b} 2$ (3 equiv.).

Other commercially available aryl dichalconides (Scheme 3) were investigated. Using diphenyl diselenide, electron-rich (29) and electron-poor (30) aryl iodides were coupled in moderate $(57 \%$ and $52 \%)$. Amide functionality on the para position was tolerated to give 31 (42\%). Importantly, heteroaromatic halides also cross-coupled in moderate to good yields. Indeed 2bromopyridine and 3-iodopyridine afforded products 32 and 33 (43\% and 51\%). Quinolines and bipyridines were welltolerated affording products $\mathbf{3 4 - 3 7}$ in moderate to good yields, emphasizing potential application of this method to drug discovery. One-step disubstitution of 2,6-dibromopyridine also provided product 39 in moderate yield (46\%). Attempting to cross-couple aryl iodides with complex ester functionalities and natural product moieties also proved to be successful, generating isoborneol (40) and menthol (41) derivatives $(60 \%$ and $49 \%$ ). Finally, diphenyl ditelluride was also investigated as a coupling partner and afforded desired products 42-47 (32$79 \%$ ), further demonstrating that the method presented herein works across group 16 elements. Importantly the synthesis of these diaryl tellurides tolerated heteroatoms, amide functionalities, and worked for both aryl bromides and iodides (Scheme 3).

To investigate the mechanism of this transformation we performed UV-vis spectroscopy experiments on various samples of 4-iodoanisole (1a) and tert-butoxides and $\mathrm{NaH}$ in DMSO (Scheme 4A, see full details in the Supporting Information $\mathrm{S} 24-27)$. As we increased the equivalency of $\mathrm{KO} t \mathrm{Bu}$ in our solution of 1a in DMSO, we observed the formation of a new peak $\left(\lambda_{\max }=329 \mathrm{~nm}\right.$; shoulder: $\left.\lambda=360 \mathrm{~nm}\right)$. Importantly, an identical peak was formed when $\mathrm{KO} t \mathrm{Bu}$ was replaced with $\mathrm{NaH}\left(\lambda_{\max }=328 \mathrm{~nm}\right.$; shoulder: $\left.\lambda=360 \mathrm{~nm}\right)$ (Scheme 4A), indicating that the resulting EDA complex formed herein does not involve $\mathrm{K}^{+}$or ${ }^{-} \mathrm{O} t \mathrm{Bu}$. Instead, we propose that this peak results from the absorption of an EDA complex between the dimsyl anion and the aryl halide $\mathbf{1 a .}$

Scheme 4. (A) UV-vis measurements, (B) Aryl radical initiation. (C) Additional reaction screens.
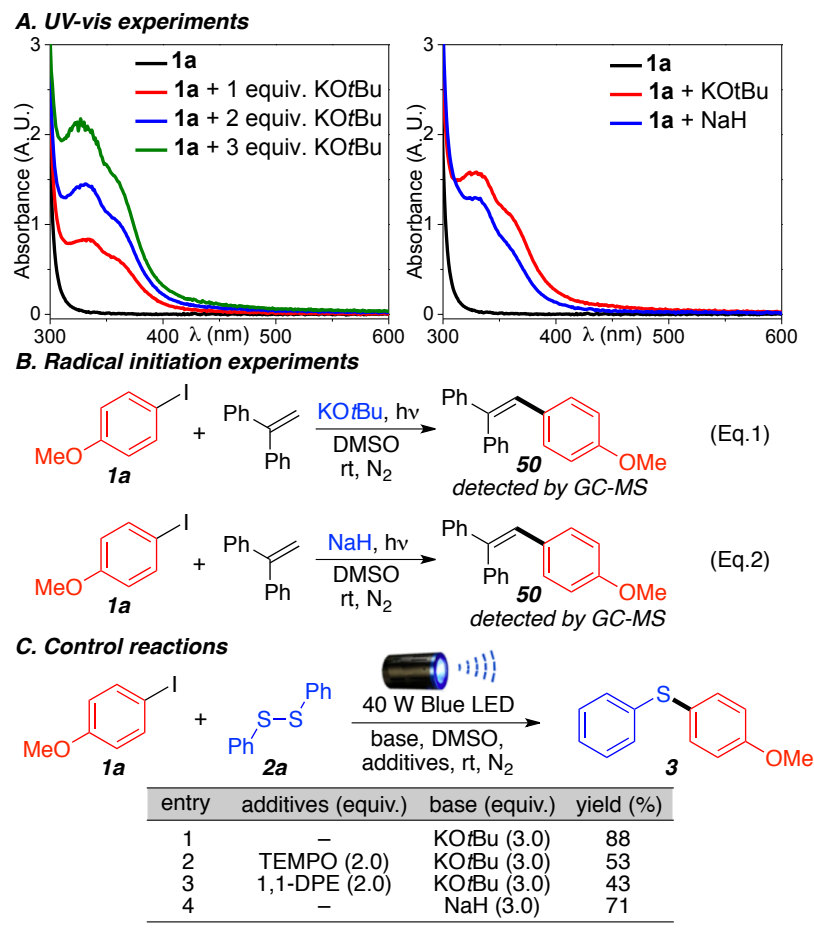

We performed additional experiments to verify that aryl halide radical initiation can take place in the absence of thiolates ${ }^{2 \mathrm{~d}}$ or $\mathrm{KO} t \mathrm{Bu}$ (Scheme 4B, Eq.1 \& Eq.2). A mixture of $\mathbf{1 a}$ and $\mathrm{KO} t \mathrm{Bu}$ in $\mathrm{DMSO}$ under blue-light irradiation generates aryl radicals trapped using 1,1-diphenylethylene (1,1-DPE) to form product 50. Replacing $\mathrm{KO} t \mathrm{Bu}$ by $\mathrm{NaH}$ under identical conditions also generated the desired aryl radicals. The use of radical quenchers, such as TEMPO and 1,1-DPE (Scheme 4C), lead to lower yields for the desired product $\mathbf{3}$. However, using $\mathrm{NaH}$ as a base did not significantly affect the C-S crosscoupling reaction and afforded the desired product in $71 \%$ yield. These results further suggest that an EDA complex between dimsyl anion and aryl halide is responsible for the observed reactivity.

Finally, to support these observations, we performed time dependent-density functional theory (TD-DFT) calculations involving a $\pi-\pi$ interaction between the dimsyl anion and the aryl halide where the shortest distance between the moieties is 
$3.5 \AA$ (see Supporting Information, S28-34). Results show that the least energetic electronic transition appears at $392 \mathrm{~nm}$ and is responsible for the observed visible-light absorption. This transition has a charge-transfer excitation character originating from the dimsyl anion molecular orbital (MO) $\pi_{\text {Номо }}$ to the aryl halide MOs $\sigma_{\mathrm{LUMO}}, \pi_{\mathrm{LUMO}+1}$ and $\pi_{\mathrm{LUMO}+2}$ with a $14 \%, 74 \%$, and $8 \%$ contribution, respectively. Based on previous reports of $\mathrm{KO} t \mathrm{Bu}$ performing SET, ${ }^{11}{ }^{16}$ we performed various DFT calculations with analogous complexes involving ${ }^{-} \mathrm{O} t \mathrm{Bu}$ and aryl iodide (see supporting information S34-42). Unfortunately neither halogen-bonded intermediates nor anion $-\pi$ complexes modeled in our study had charge-transfer character, further eroding a potential involvement of ${ }^{-} \mathrm{O} t \mathrm{Bu}$ in the SET step.

Based on the calculations and mechanistic experiments presented above, we propose that in presence of base, DMSO generates dimsyl anions capable of forming an EDA complex with the aromatic halide (Scheme 5). A charge-transfer from the dimsyl anion to the aryl halide forms aryl radical anion and dimsyl radical. Loss of iodide generates aryl radical that then couples with disulfide or thiyl radical to give the desired product. Decomposition of the dimsyl radical via reactions with tert-butanol, disulfide or by other processes lead to the formation of minor impurities.

Scheme 5. Proposed Mechanism

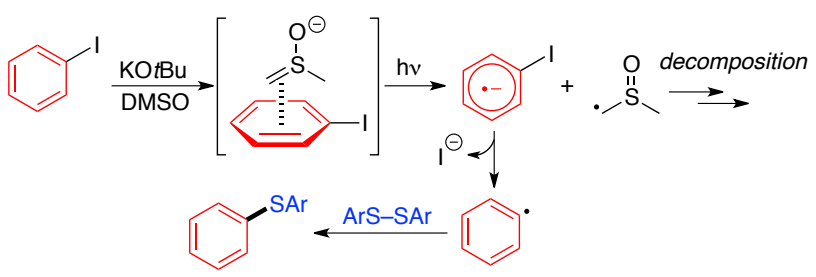

In summary, we have developed a simple and efficient visible-light-induced cross-coupling reaction between aryl halides and diaryl disulfide, diselenides, and ditellurides to form unsymmetrical chalcones without using transition-metal catalysts, a photocatalyst, or added ligands. The transformation proceeds under mild reaction conditions, exhibits good tolerance of functional groups, and can be applied to cross-couplings of heteroaromatic halides. We also have postulated a novel mechanism to account for these transformations based on control experiments, a UV-Vis spectroscopy investigation, and TD-DFT calculations. We surmise that an EDA complex between dimsyl anion and the aryl halide is formed during the reaction. Upon absorbance of visible-light, the EDA complex undergoes a charge transfer that leads to loss of halide and formation of an aryl radical. From this observation, we envision future dimsyl anion enabled cross-coupling reactions of aryl halides with different aryl radical trapping agents.

\section{ASSOCIATED CONTENT}

\section{Supporting Information}

The Supporting Information is available free of charge on the ACS Publications website.

\section{AUTHOR INFORMATION}

\section{Corresponding Author}

*E-mail: slaulhe@iupui.edu.

ORCID Sébastien Laulhé: 0000-0003-4510-1916

\section{Author Contributions}

The manuscript was written with contributions from all authors. Notes

The authors declare no competing financial interest.

\section{ACKNOWLEDGMENT}

This publication was made possible, with support from the National Institute of Dental \& Craniofacial Research grant number 5R21DE029156-02. This research was supported in part by Lilly Endowment, Inc. through its support for the Indiana University Pervasive Technology Institute. The authors also want to acknowledge Drs. M. K. Brown and S. Cook (IU Bloomington) and graduate student S. K. Dorn for helping with compound characterization.

\section{REFERENCES}

(1) (a) Feng, M.; Tang, B.; Liang, S.H.; Jiang, X. Sulfur in Medicinal Chemistry. Curr. Top. Med. Chem. 2016, 16, 1200-1216. (b) Banerjee, B.; Koketsu, M. Recent Developments in the Synthesis of Biologically Relevant Selenium-Containing Scaffolds. Coord. Chem. Rev. 2017, 339, 104-127. (c) Nogueira, C. W.; Zeni, G.; Rocha, J. B. T. Organoselenium and Organotellurium Compounds: Toxicology and Pharmacology. Chem. Rev. 2004, 104, 62556285. (d) Devendar, P.; Yang, G.-F. Sulfur-Containing Agrochemicals. Top. Curr. Chem. 2017, 375, 82. (e) Rahate, A. S.; Nemade, K. R.; Waghuley, S. A. Polyphenylene Sulfide (PPS) : State of the Art and Applications. Rev. Chem. Eng. 2013, 29, 471-489.

(2) (a) Beletskaya, I. P.; Ananikov, V. P. TransitionMetal-Catalyzed $\mathrm{C}-\mathrm{S}, \mathrm{C}-\mathrm{Se}$, and $\mathrm{C}-\mathrm{Te}$ Bond Formation via Cross-Coupling and Atom-Economic Addition Reactions. Chem. Rev. 2011, 111, 1596-1636. (b) Liu, J.; Tian, M.; Li, Y.; Shan, X.; Li, A.; Lu, K.; Fagnoni M.; Protti, S.; Zhao, X. Metal-Free Synthesis of Unsymmetrical Aryl Selenides and Tellurides via Visible Light-Driven Activation of Arylazo Sulfones. Eur. J. Org. Chem. 2020, 73587367. (c) Wang, H.; Chen, S.; Liu, G.; Guan, H.; Zhong, D.; Cai, J.; Zheng, Z.; Mao, J.; Walsh, P. J. Synthesis of Diaryl Selenides via Palladium-Catalyzed Debenzylative CrossCoupling of Aryl Benzyl Selenides with Aryl Bromides. Organometallics 2018, 37, 4086-4091. (d) Liu, B.; Lim, C.-H.; Miyake, G. M. Visible-light-promoted C-S crosscoupling via intermolecular charge transfer. J. Am. Chem. Soc. 2017, 139, 13616-13619. (e) Lemir, I. D.; CastroGodoy, W. D.; Heredia, A. A.; Schmidt, L. C.; Argüello, J. E. RSC Adv. 2019, 9, 22685-22694.

(3) For thiol coupling to aryl halides: (a) Jones, K. D.; Power, D. J.; Bierer, D.; Gericke, K. M.; Stewart, S. G. Nickel Phosphite/Phosphine-Catalyzed C-S CrossCoupling of Aryl Chlorides and Thiols. Org. Lett. 2018, 20, 208-211. (b) Correa, A.; Carril, M.; Bolm, C. IronCatalyzed S-Arylation of Thiols with Aryl Iodides. Angew. Chem., Int. Ed. 2008, 47, 2880-2883. (c) Wong, Y.-C.; Jayanth, T. T.; Cheng, C.-H. Cobalt-Catalyzed Aryl Sulfur Bond Formation. Org. Lett. 2006, 8, 5613-5616. (d) Fernandez-Rodriguez, M. A.; Shen, Q.; Hartwig, J. F. A General and Long-Lived Catalyst for the Palladium-Catalyzed Coupling of Aryl Halides with Thiols. J. Am. Chem. Soc. 2006, 128, 2180-2181. (e) Itoh, T.; Mase, T. A General Palladium-Catalyzed Coupling of Aryl Bromides/Triflates and Thiols. Org. Lett. 2004, 6, 4587-4590. 
(4) For selenide coupling to aryl halides: (a) Wu, S.; Shi, J.; Zhang, C.-P. Cu-Mediated Arylselenylation of Aryl Halides with Trifluoromethyl Aryl Selenonium Ylides. Org. Biomol. Chem. 2019, 17, 7468-7473. (b) Hu, D.; Liu, M.; Wu, H.; Gao, W.; Wu, G. Copper-catalyzed diarylation of Se with aryl iodides and heterocycles. Org. Chem. Front. 2018, 5, 1352- 1355. (c) Gao, C.; Wu, G.; Min, L.; Liu, M.; Gao, W.; Ding, J.; Chen, J.; Huang, X.; Wu, H. CopperCatalyzed Three-Component Coupling Reaction of Azoles, Se Powder, and Aryl Iodides. J. Org. Chem. 2017, 82, 250255.

(5) Hegedus, L. L.; McCabe, R. W. Catalyst Poisoning; Marcel Dekker: New York, 1984.

(6) Node, M.; Kajimoto, T. Development of Odorless Organosulfur Reagents and Asymmetric Reaction Using Odorless Thiols. Heteroat. Chem. 2007, 18, 572-683.

(7) (a) Beletskaya, I. P.; Sigeev, A. S.; Peregudov, A. S.; Petrovskii, P. V. New approaches to the synthesis of unsymmetrical diaryl selenides. J. Organomet. Chem. 2000, 605, 96-101. (b) Nishiyama, Y.; Tokunaga, K.; Sonoda, N. New Synthetic Method of Diorganyl Selenides: PalladiumCatalyzed Reaction of $\mathrm{PhSeSnBu}_{3}$ with Aryl and Alkyl Halides. Org. Lett. 1999, 1, 1725-1727.

(8) (a) Li, Y.; Wang, M.; Jiang, X. Controllable Sulfoxidation and Sulfenylation with Organic Thiosulfate Salts via Dual Electron- and Energy-Transfer Photocatalysis. ACS Catal. 2017, 7, 7587-7592. (b) Jiang, M.; Li, H.; Yang, H.; $\mathrm{Fu}, \mathrm{H}$. Room-Temperature Arylation of Thiols: Breakthrough with Aryl Chlorides. Angew. Chem., Int. Ed. 2017, 56, 874-879. (c) Johnson, M. W.; Hannoun, K. I.; Tan, Y.; Fu, G. C.; Peters, J. C. A Mechanistic Investigation of the Photoinduced, Copper-Mediated Cross-Coupling of an Aryl Thiol with an Aryl Halide. Chem. Sci. 2016, 7, 4091-4100. (d) Oderinde, M. S.; Frenette, M.; Robbins, D. W.; Aquila, B.; Johannes, J. W. Photoredox Mediated Nickel Catalyzed Cross-Coupling of Thiols With Aryl and Heteroaryl Iodides via Thiyl Radicals. J. Am. Chem. Soc. 2016, 138, 17601763. (e) Jouffroy, M.; Kelly, C. B.; Molander, G. A. Thioetherification via Photoredox/Nickel Dual Catalysis. Org. Lett. 2016, 18, 876-879. (f) Uyeda, C.; Tan, Y.; Fu, G. C.; Peters, J. C. A New Family of Nucleophiles for Photoinduced, Copper-Catalyzed Cross-Couplings via SingleElectron Transfer: Reactions of Thiols with Aryl Halides Under Mild Conditions $\left(0^{\circ} \mathrm{C}\right)$. J. Am. Chem. Soc. 2013, 135, 9548-9552.

(9) (a) Bu, M.-J.; Lu, G.-P.; Jiang, J.; Cai, C. Merging Visible-Light Photoredox and Micellar Catalysis: Arylation Reactions with Anilines Nitrosated in situ. Catal. Sci. Technol. 2018, 8, 3728-3732. (b) Kundu, D.; Ahammed, S.; Ranu, B. C. Visible Light Photocatalyzed Direct Conversion of Aryl-/Heteroarylamines to Selenides at Room Temperature. Org. Lett. 2014, 16, 1814-1817. (c) Kobiki, Y.; Kawaguchi, S.-i.; Ohe, T.; Ogawa, A. Photoinduced Synthesis of Unsymmetrical Diaryl Selenides from Tri- arylbismuthines and Diaryl Diselenides. Beilstein J. Org. Chem. 2013, 9, 1141-1147.

(10) Bunnett, J. F.; Creary, X. Nucleophilic Replacement of Two Halogens in Dihalobenzenes Without the Intermediacy of Monosubstitution Products. J. Org. Chem. 1974, 39, 3611-3612.

(11) (a) Yanagisawa, S.; Ueda, K.; Taniguchi, T.; Itami, K. Potassium $t$-Butoxide Alone Can Promote the Biaryl Coupling of Electron-Deficient Nitrogen Heterocycles and Haloarenes. Org. Lett., 2008, 10, 4673-4676. (b) Shirakawa, E.; Itoh, K.-I.; Higashino, T.; Hayashi, T. tert-ButoxideMediated Arylation of Benzene with Aryl Halides in the Presence of a Catalytic 1,10-Phenanthroline Derivative. $J$. Am. Chem. Soc. 2010, 132, 15537-15539. (c) Liu, W.; Cao, H.; Zhang, H.; Zhang, H.; Chung, H. K.; He, C.; Wang, H.; Kwong, F. Y.; Lei, A. Organocatalysis in Cross-Coupling: DMEDA-Catalyzed Direct C-H Arylation of Unactivated Benzene. J. Am. Chem. Soc. 2010, 132, 16737-16740. (c) Roman, D. S.; Takahashi, Y.; Charette, A. B. Potassium tert-Butoxide Promoted Intramolecular Arylation via a Radical Pathway. Org. Lett., 2011, 13, 3242-3245.

(12) (a) Budén M. E.; Guastavino, J. F.; Rossi, R. A. Room-Temperature Photoinduced Direct C-H-Arylation via Base-Promoted Homolytic Aromatic Substitution. Org. Lett., 2013, 15, 1174-1177. (b) Guastavino, J. F.; Budén M. E.; Rossi, R. A. Room-Temperature and Transition-MetalFree Mizoroki-Heck-type Reaction. Synthesis of E-stilbene by Photoinduced C-H Functionalization. J. Org. Chem. 2014, 79, 9104-9111. (c) Yuan, J.; To, W.-P.; Zhang, Z.-Y.; Yue, C.-D.; Meng, S.; Chen, J.; Liu, Y.; Yu, G.-A.; Che, C.M. Visible-Light-Promoted Transition-Metal-Free Phosphinylation of Heteroaryl Halides in the Presence of Potassium tert-Butoxide. Org. Lett. 2018, 20, 7816-7820. (d) Ding, T.-H.; Qu, J.-P.; Kang, Y.-B. Visible-Light-Induced, Base-Promoted Transition-Metal-Free Dehalogenation of Aryl Fluorides, Chlorides, Bromides, and Iodides. Org. Lett. 2020, 22, 3084-3088.

(13) Barham, J. P.; Coulthard, G.; Emery, K. J.; Doni, E.; Cumine, F.; Nocera, G.; John, M. P.; Berlouis, L. E. A.; McGuire, T.; Tuttle, T.; Murphy, J. A. KOtBu: A Privileged Reagent for Electron Transfer Reactions? J. Am. Chem. Soc. 2016, 138, 7402-7410.

(14) Rohe, S.; Révol, G.; Marmin, T.; Barriault, D.; Barriault L. Single-Electron Transfer from Dimsyl Anion in the Alkylation of Phenols. J. Org. Chem. 2020, 85, 2806-2813.

(15) Budén M. E.; Guastavino, J. F.; Puiatti M.; Rossi, R. A. Initiation in Photoredox $\mathrm{C}-\mathrm{H}$ Functionalization Reactions. Is Dimsyl Anion a Key Ingredient? J. Org. Chem. 2017, 82, 8325-8333.

(16) Pan, L.; Elmasry, J.; Osccorima, T.; Cooke, M. V.; Laulhé, S. Photochemical Regioselective C $\left(\mathrm{sp}^{3}\right)-\mathrm{H}$ Amination of Amides Using $N$-haloimides. Org. Lett. 2021, 23, 3389-3393. 


\section{TOC}

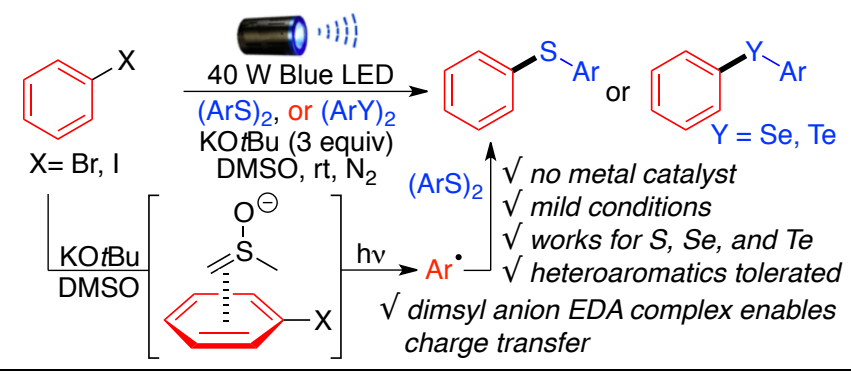

